\title{
Desenvolvendo a Lógica e Algoritmos no Ensino Médio
}

\author{
Decíola Fernandes de Sousa \\ Instituto Ciberespacial- Universidade Federal Rural da Amazônia (UFRA) \\ Avenida Presidente Tancredo Neves, No 2501 Bairro: Montese Cep: 66.077-901 \\ Belém-Pará-Brasil \\ deciola.sousa@ufra.edu.br
}

\begin{abstract}
Motivated by the experience from the course of introduction to algorithm teaching to high school students of public school through the project Developing Logic and Algorithms in School, the course focused on exercises about logic and basic algorithms. The present work is motivated by the activities that were developed along the course, the students were evaluated through tests before and after the course, they evaluated the course and and performed the assessment of themselves. The course collaborated in the process of teaching and learning of students in degree in LINCENCIATURA in computing. All results were satisfactory, which motivates us to continue the project.
\end{abstract}

Resumo. Este artigo apresenta uma experiência obtida no curso de introdução a algoritmo oferecido aos alunos do ensino médio de uma escola pública através do projeto Desenvolvendo a Lógica e Algoritmos na Escola. O curso focou em exercícios de lógica e de algoritmos básicos. Os alunos foram avaliados através de testes antes e depois do curso, avaliaram o curso e realizaram uma autoavaliação. $O$ curso colaborou no processo de ensino e aprendizagem de alunos do curso de licenciatura em computação. Todos os resultados foram satisfatórios, o que nos motiva a continuar o projeto.

\section{Introdução}

Antes de aprender a programar é necessário desenvolver o raciocino lógico através de algoritmos. Mas o que é lógica? O que é algoritmo? Para Forbellone, lógica é a arte de bem pensar e algoritmo é uma sequência de passos que visam atingir um objetivo bem definido [Forbellone 2005].

A palavra lógica é de origem grega, logos, que significa linguagem racional, ou seja, possibilita que se chegue a uma conclusão por meio de encadeamentos [Puga 2003]. A lógica é aplicada em diversas áreas do conhecimento, principalmente na computação, tanto no nível de hardware (parte física), como no nível de software (programas). A lógica na educação possibilita o uso do computador como um meio que permite ao aluno ter outra possibilidade no processo de construção da aprendizagem. $\mathrm{O}$ grande desafio da educação é de se utilizar a informática como complemento das matérias e também trazê-la para a sala de aula implica em mudar o sistema e a forma educacional como um todo.

Para Pereira Junior et al. (2006) um dos gargalos dos cursos de graduação da área de computação e informática é o ensino de algoritmos e programação. O problema também acontece com os cursos de engenharia, ou seja, essas disciplinas possuem um 
alto nível de reprovação. O discente quando ingressa no curso superior, sente dificuldade em desenvolver o raciocínio lógico e em criar programas, apesar de viver seguindo passos.

O rompimento com o paradigma tradicional e o surgimento do construtivismo, enfatiza a participação e experimentação do sujeito na construção de seu próprio conhecimento, por meio de suas interações, faz com que os computadores passem a ser utilizados no contexto educativo [Moraes 1997]. De forma geral, sabe-se que transformar o ensino é uma tarefa árdua que exige do docente pesquisa, conhecimento e, acima de tudo, o apoio através de políticas públicas. Ao docente é atribuída a missão de acompanhar essas mudanças, ampliar seus métodos educacionais e possibilitar, dessa forma, maior interação entre o ensino e aprendizagem.

O aspecto central da computação é a habilidade do aluno sistematizar a solução de um problema através de um raciocínio lógico. Acredita-se que o desenvolvimento do raciocínio lógico no ensino médio motivará os alunos a permanecerem na Escola, no ingresso a um curso superior e ajudará nas disciplinas programação.

Segundo as Diretrizes Curriculares Nacionais (DCN), o egresso do Curso de Licenciatura em Computação deve possuir a capacidade de atuar como docente e estimular a aprendizagem de ensino da computação, mas para que isso aconteça é necessário incluir na formação a oportunidade [Brasil 2012].

Nas diversas alternativas acerca das mudanças necessárias, para melhorar a aprendizagem dos graduandos em licenciatura em computação, pode-se considerar inúmeras possibilidades, no entanto, poucas iniciativas têm se mostrado tão animadoras quanto aquelas que buscam a aprendizagem através de prática como o Programa Institucional de Bolsas de Iniciação á Docência (PIBID).

O artigo tem o objetivo de apresentar os resultados do curso de introdução ao raciocínio lógico e do desenvolvimento de algoritmos para alunos do ensino médio de escola pública do estado na região metropolitana de Belém. O projeto aconteceu com alunos do Curso de Licenciatura em Computação, através do Programa Institucional de Bolsas de Iniciação à Docência. Especificamente, o interesse é analisar se há aceitação ou não dos alunos do ensino médio, além de propor oportunidades de aprender e vivenciar o ensino e a prática dos conceitos de lógica e algoritmo.

O artigo está organizado da seguinte maneira forma. A seção 2 apresenta trabalhos relacionados ao artigo, na seção 3 é apresentada a metodologia do projeto, a seção 4 discute os resultados e as considerações finais estão na seção 5.

\section{Trabalhos Relacionados}

Uma experiência obtida em uma oficina de introdução a programação oferecida aos alunos do ensino médio da região do Vale do Mamanguape da Paraíba é descrita por Marques et al. (2011), com o objetivo de introduzir noções de programação através de exemplos práticos e jogos através da programação em Phyton, a ideia dos autores é atrair alunos para os cursos de computação e ajudar na formação dos licenciados em computação. A oficina teve a duração de 16 horas, dezesseis alunos concluíram e avaliaram como positiva e todos declararam que o interesse pela área de informática aumentou após a mesma. Um dos pontos relevantes neste trabalho é que o artigo apresenta alguns ajustes na primeira prática e que são válidos para todos. 
Em Leal e Lozano (2009) é proposto a inclusão de algoritmo no ensino médio através de oficina, para alunos do $1^{\circ}$ e $2^{\circ}$ ano do CEFET Química - Unidade Duque de Caxias, no Rio de Janeiro e de uma Escola privada localizada no centro de Duque de Caxias, Os autores realizaram uma pesquisa com trinta alunos, trabalharam conceitos relacionados à Modelagem Matemática e Modelação Matemática, e noções da Teoria dos Grafos. O artigo enfatiza a importância do pensamento algoritmo na atualidade e a viabilidade de aprender algoritmo no ensino médio. O interessante da proposta é realizar a interdisciplinaridade com os alunos de uma maneira agradável e prazerosa para todos os participantes.

A experiência no desenvolvimento de um jogo sério para familiarizar alunos do ensino médio com os conceitos de programação é tratado por Scaico et al. (2012), para os autores aprender programação não é uma tarefa fácil, mas o jogo permite que os estudantes tenham o primeiro contato com a programação e consequentemente aprendam a programar de maneira diferente e estimulante. Além disso, o artigo apresenta o jogo e proposta para realizar testes com alunos do ensino médio.

A experiência em um projeto de extensão é relatada por Garcia et al. (2008), o objetivo é proporcionar aos alunos do ensino médio a oportunidade de adquirir competências relacionadas ao desenvolvimento do raciocínio lógico, especificamente na resolução de problemas por meio de Algoritmos e Estruturas de Dados; os autores pretendem motivar os participantes a continuar seus estudos na área de Computação e Informática. O projeto teve como público alvo alunos do ensino médio de escola pública ou privada. No total, foram selecionados trinta e três alunos, sendo a maioria da rede pública. O curso teve a duração de 10 meses com 228 horas. Os algoritmos foram desenvolvidos em Português Estruturado (Portugol) e a linguagem de programação foi C. A iniciativa é de extrema importância, não só para a área de Computação, mas também para a sociedade como um todo.

Pereira Junior et al. (2005) apresentam um estudo de introdução a programação no ensino médio com o objetivo de ajudar o ingresso e a permanência do aluno no curso superior na área de computação. Os autores desenvolveram uma oficina de lógica de programação, com alunos do segundo ano do ensino médio de uma escola no Rio de Janeiro, com duração de trinta e seis horas. O curso apresentou uma proposta interessante, pois antes de ensinar programação os alunos desenvolveram problemas evolvendo o raciocínio lógico, bem como, utilizaram jogos de raciocínio lógico para tornar a aprendizagem mais lúdica, estimulando os alunos no desenvolvimento das tarefas. Posteriormente, o curso abordou a parte conceitual e construção de algoritmos utilizando a linguagem Pascal. Embora o curso apresentasse uma boa proposta, apenas cinco alunos concluíram e apresentaram interesse em ingressar no ensino superior nas áreas da computação.

Este artigo apresenta uma proposta diferente das anteriores por incluir resultados de testes de lógica realizados no início e no fim do curso, teste de algoritmo, além da avaliação do curso feita pelos alunos participantes.

\section{Métodos}

O método aplicado a este trabalho tem como fundamento uma abordagem qualitativa, apesar de possuir dados quantitativos, a respeito do curso de Introdução a Algoritmos no Ensino Médio ofertado pelo Programa Institucional de Bolsa de Iniciação à Docência 
(PIBID) para alunos do Ensino Médio em uma escola estadual localizada no município de Belém-Pará, com a participação de 5 alunos do curso de Licenciatura em Computação e de uma professora da escola na supervisão.

A pesquisa realizada foi exploratória, na qual foram utilizados para a análise os dados obtidos através de testes de desempenho dos alunos no curso e de satisfação dos alunos que participaram do projeto. Os testes de desempenho foram utilizados para comparar os resultados na resolução de problemas lógicos que necessitem de reflexão dos alunos e o de satisfação para observar onde o projeto deve melhorar.

A Escola parceira no projeto possui, no ano de 2013, 15 turma do ensino médio no turno da manhã e 11 turmas no turno da tarde. No turno da manhã são seis turmas de $1^{\circ}$ ano, cinco de $2^{\circ}$ ano e quatro de $3^{\circ}$ ano. No turno da tarde são seis turmas de $1^{\circ}$ ano, duas do $2^{\circ}$ e três do $3^{\circ}$ ano. O total de alunos matriculados no ensino médio é 651 , sendo 409 no turno da manhã e 242 no turno da tarde.

Para a realização do curso foi ofertada uma turma no horário da tarde para todos os alunos do ensino médio da Escola que estudam no turno da manhã. A divulgação do curso aconteceu durante uma semana, no horário de aula, nas salas de todas as turmas de ensino médio da Escola, onde a equipe conversava antes com o professor da turma explicando o motivo da divulgação. Entregava-se o formulário de inscrição para que os alunos interessados em participar trouxessem no outro dia assinado pelo responsável.

No curso se inscreveram 48 alunos, sendo 36 do primeiro ano, 04 do segundo ano, e 08 do terceiro ano, ou seja, $75 \%$ dos matriculados são do $1^{\circ}$ ano, $17 \%$ do $2^{\circ}$ e $8 \%$ de $3^{\circ}$. Do primeiro ano 24 do sexo feminino e 12 do sexo masculino a idade média de 15 anos, sendo 14 anos a menor idade e a maior 17 anos. Do segundo todos os 4 do sexo masculino com a idade média de 17 anos, a menor idade 16 e a maior 18. Do terceiro ano se inscreveram 8 alunos, 4 do sexo masculino e 4 do sexo feminino com idade média de 18 anos, menor 16 e a maior 20.

O curso começou com 34 alunos, 28 do primeiro ano, 21 do sexo feminino e 7 do sexo masculino, 3 do segundo ano, todos do sexo masculino e 3 do terceiro, 1 do sexo feminino e 2 do sexo masculino. $O$ curso aconteceu no contra turno que os alunos estudavam, a carga total de 40 horas, com três horas de aulas diárias durante 14 dias em uma sala de aula da Escola, sendo o último dia reservado para avaliação, entrega dos certificados e um lanche.

No primeiro dia do curso apresentou-se o objetivo, a importância do controle da frequência e as avaliações que seriam realizadas durante o curso. Somente um aluno já havia feito um curso programação para computadores em Linguagem de Marcação de Hipertexto (HTML), porém nenhum aluno sabia o que era um algoritmo.

A abordagem orientada a problemas foi escolhida para o curso [Nunes 2007]. As quarenta horas do curso foram dividida em, uma hora para apresentar os objetivos, conteúdo e a necessidade das avaliações, quatro horas de exercícios lógicos, quatro horas de introdução a algoritmo, dez horas para a estrutura sequencial e quinze horas para estrutura e seleção, todas as aulas com teorias e práticas, além de seis horas de avaliações, perfazendo o total de quarenta horas. As aulas aconteceram de segunda a sexta-feira com três horas de aula por dia nos primeiros horários da tarde durante quatorze dias, no último dia aconteceu a entrega dos certificados, um lanche e brindes para os alunos que se destacaram durante o curso. 
Aconteceram três avaliações valendo dez, uma no terceiro dia contendo português, matemática e lógica e no final do curso uma com questões de português, matemática e lógica e uma de algoritmo, sendo uma questão da estrutura sequencial e outra da estrutura de seleção, todas diferentes das estudadas em sala. Cada avaliação possuía cinco questões, valendo dois pontos cada, sendo duas de nível fácil, duas de nível médio e uma de nível difícil. Trabalhou-se com notas de zero a dez, depois se converteu para conceito obedecendo ao seguinte critério, de dez a nove pontos o conceito é ótimo, de sete a oito pontos o conceito é bom, de cinco a seis pontos é regular, de três a quatro pontos é ruim e de zero a dois pontos é péssimo.

Do total de inscritos no curso $71 \%$ começaram e $82 \%$ concluíram o curso, ou seja, 28 alunos, sendo 24 do primeiro ano, um do segundo e três terceiro ano. Do primeiro ano18 do sexo feminino e 6 do sexo masculino, do segundo ano 1 do sexo masculino e do terceiro ano 1 do sexo feminino e 2 do sexo masculino.

As aulas teóricas aconteceram em uma sala de aula cedida pela escola e a prática no laboratório de informática. Os algoritmos através do software Portugol. No último dia os alunos da Escola que concluíram o curso receberam certificados, assim como a professora supervisora do projeto na escola e os alunos do curso de graduação em Licenciatura em Computação.

\section{RESULTADOS E DISCUSSÃO}

Com o objetivo de comprovar ou não a hipótese a respeito do curso de Introdução a Algoritmos no Ensino Médio, aplicou-se no último dia de aula um questionário preenchido de forma anônima pelos alunos da escola que concluíram o projeto, vinte e oito alunos responderam, os resultados estão na Figura 1.

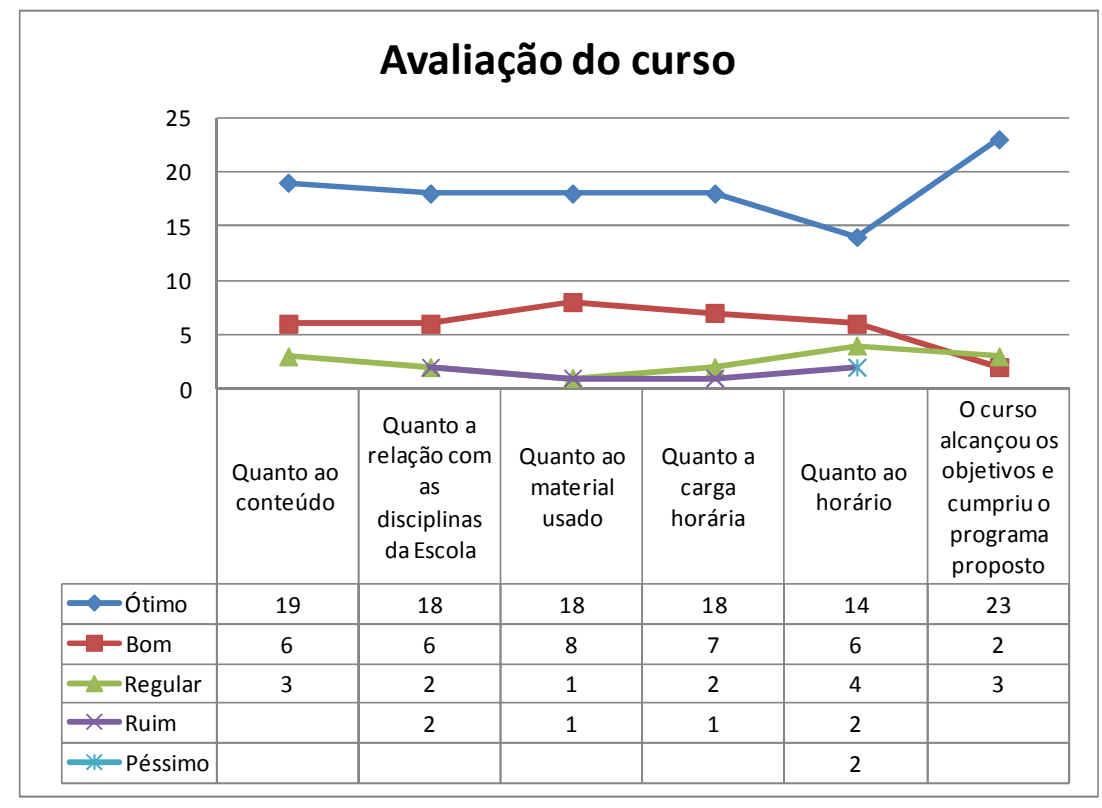

Figura 1. Avaliação quanto ao curso. 
Quanto ao conteúdo ministrado no curso, $68 \%$ dos alunos da escola classificaram como ótimo, $21 \%$ como bom e $11 \%$ como regular. Na relação do curso com as disciplinas da escola, $64 \%$ consideraram ótima, $21 \%$ regular, $7 \%$ consideraram regular e ruim. $\mathrm{Na}$ avaliação do material usado no curso como datashow, quadro e laboratório $64 \%$ consideraram ótimo, $29 \%$ consideraram bom, 4\% regular e ruim, os alunos sentiram falta de um material impresso como uma apostila, por exemplo. Na avaliação da carga horária $64 \%$ consideraram ótima, $29 \%$ boa, $4 \%$ consideraram regular e ruim. Resolvemos avaliar o horário do curso, devido a distância da casa ficavam direto na escola das 7 ás 16 horas, para surpresa nossa 50\% consideraram ótimo, 21\% bom, $14 \%$ regular, $7 \%$ ruim e péssimo. $\mathrm{Na}$ avaliação dos objetivos e do programa do curso, $82 \%$ dos alunos avaliaram como ótimo, $7 \%$ bom e $11 \%$ regular, este resultado é gratificante para todos os participantes do projeto e o curso conseguiu atingir os objetivos que foram propostos.

Para investigar se o curso de lógica e algoritmos é estimulante, ou se o participante estava fazendo o curso por fazer, avaliou-se o grau de interesse de cada aluno da Escola, os resultados são mostrados na Figura 2.

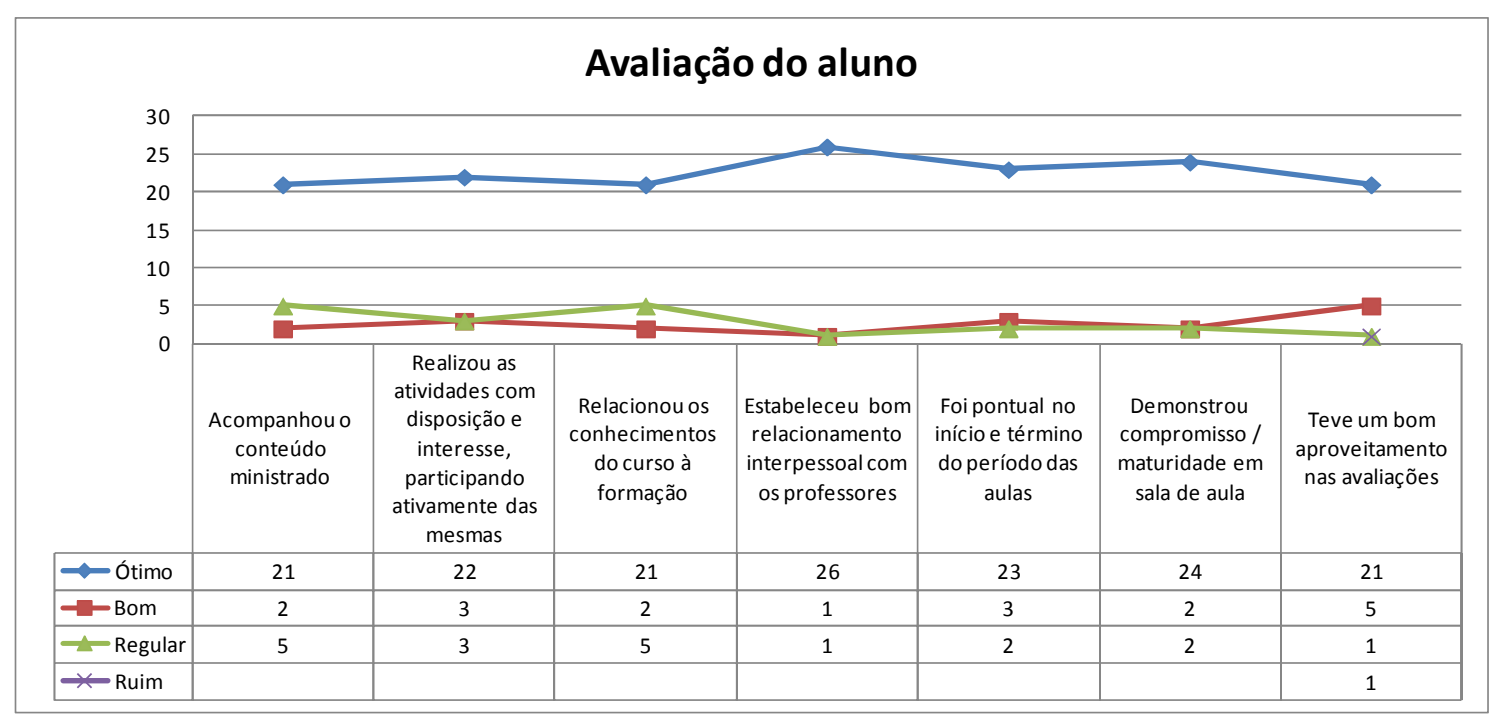

Figure 2. Avaliação Pessoal.

Dos alunos que concluíram o curso, para $75 \%$ o acompanhamento foi ótimo, para $7 \%$ foi bom e para $18 \%$ foi regular. Quanto as atividades propostas no curso $79 \%$ realizaram de maneira ótima, $11 \%$ de maneira boa ou regular. No relacionamento do curso com a formação escolar, $100 \%$ avaliaram que existe, principalmente com a matemática devido os algoritmos estudados que tratavam de cálculos básico, para $75 \%$ a relação é ótima, para $7 \%$ é boa e para $18 \%$ é regular. Quanto a pontualidade para $82 \%$ avaliaram como ótima, $11 \%$ boa e $7 \%$ regular, o fato de poucos irem almoçar em casa contribuiu com a pontualidade. Quanto ao compromisso e maturidade nas aulas do curso, tanto teórica quanto prática $86 \%$ tiveram um ótimo comportamento, para $7 \%$ o comportamento bom e regular. Para as avaliações realizadas durante o curso, $75 \%$ consideraram o aproveitamento ótimo, para $18 \%$ bom e para $4 \%$ regular ou ruim. No total os alunos que concluíram o curso se avaliaram de maneira satisfatória. 
Os alunos realizaram avaliações de português, matemática e lógica no início e no final do curso e uma de algoritmo, porém o objetivo do artigo é avaliar o projeto, os dados apresentados nas Figuras 3 e 4 são os das avaliações de lógica e da avaliação de algoritmo.

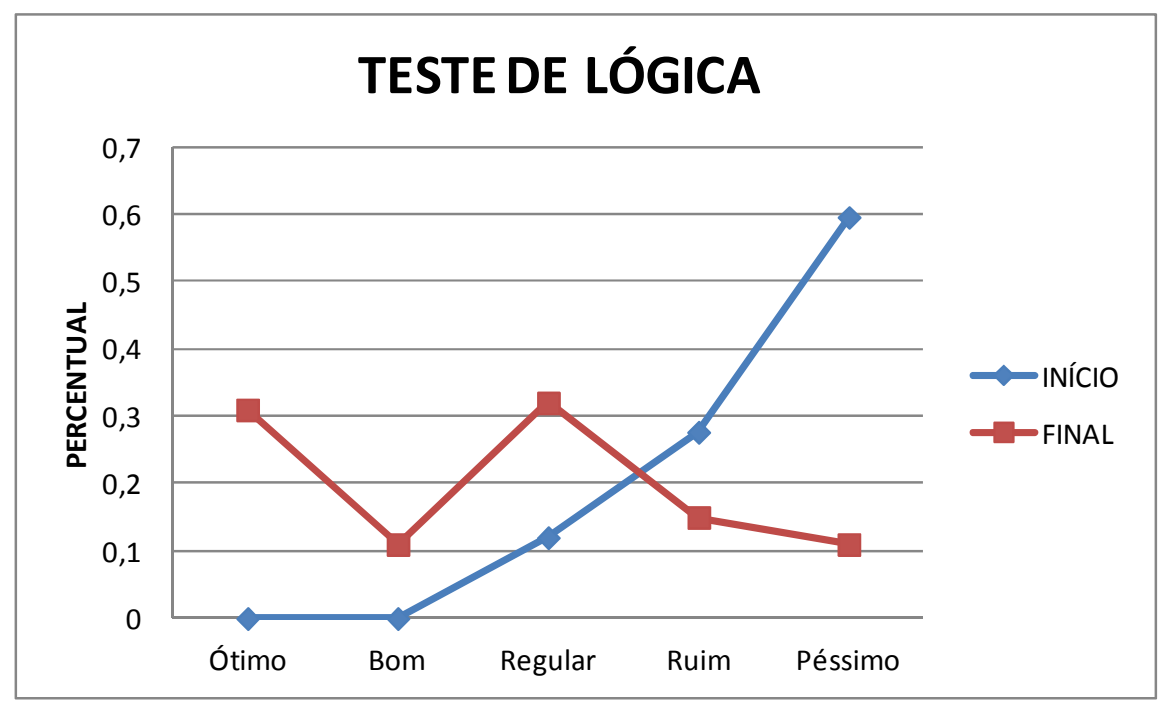

Figure 3. Resultado dos testes de lógica

No resultado dos testes de lógica realizado pelos alunos da escola no início do curso $12 \%$ obtiveram o rendimento regular, $28 \%$ ruim e $60 \%$ o rendimento péssimo. Mas, no final do curso $31 \%$ dos alunos conseguiram um aproveitamento ótimo, $11 \%$ bom, $32 \%$ regular, $15 \%$ ruim e $11 \%$ péssimo, os resultados demonstram uma melhora significativa, já que se uso o mesmo critério nas duas avaliações.

A Figura 4 apresenta o resultado da avaliação de algoritmos.

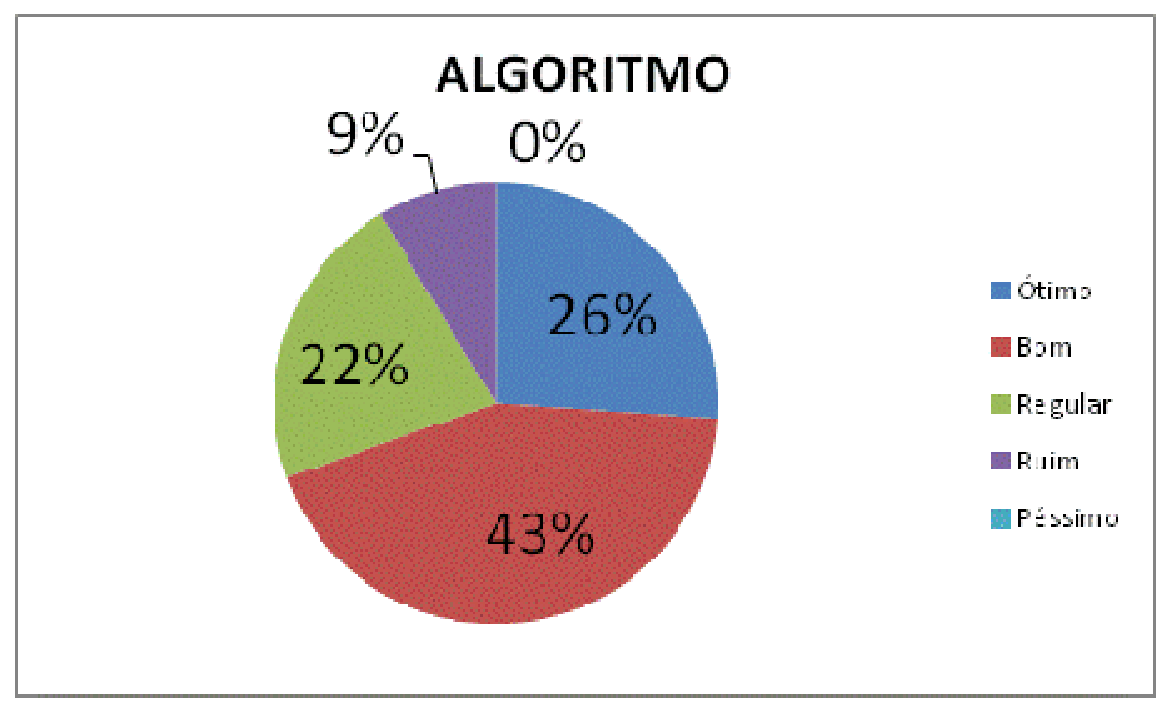

Figure 4. Avaliação dos algoritmos. 
$\mathrm{Na}$ avaliação dos dois algoritmos propostos, $26 \%$ conseguiram o rendimento ótimo, $43 \%$ bom, $22 \%$ regular e $9 \%$ ruim. Os resultados da avaliação demonstram que é possível aprender algoritmo no ensino médio.

De maneira geral os resultados foram satisfatórios. A avaliação que os alunos da Escola fizeram do curso e da participação deles no curso nos motivam a continuar com o projeto, assim como os resultados alcançados pelos alunos nos testes de lógica e de algoritmo motivam os alunos a concluir o ensino médio, pois como acontece nas Escolas muitos alunos não concluem o ensino médio por uma falta de perspectiva em cursar o ensino superior. Além da oportunidade de aprendizagem para os alunos de Licenciatura em Computação.

\section{Considerações Finais e Trabalhos Futuros}

O artigo apresenta uma análise do curso de lógica e algoritmos em uma escola pública do estado situada na região metropolitana de Belém - Pará, ministrado por docentes do curso de Licenciatura em Computação para alunos do ensino médio no contra turno, com três horas de aulas todos os dias durante quatorze dias, a carga horária total de quarenta horas.

Realizaram-se avaliações com os alunos no início e no término do curso de português, matemática e lógica e uma de algoritmo no final com duas questões uma da estrutura sequencial e outra de seleção, com o objetivo de analisar a aprendizagem e a validade do curso. Os alunos da escola avaliaram a viabilidade do curso e a participação no curso, o objetivo dessas avaliações é melhorar o projeto, nos resultados dos testes de lógica no início e no final do curso, observar-se melhoras significativas no desenvolvimento dos alunos, no primeiro teste mais da metade da turma, ou seja, $60 \%$, obtiveram conceito péssimo, mas no segundo teste, para felicidade de todos, $31 \%$ alcançaram o conceito ótimo, os alunos conseguiram desenvolver os algoritmos onde média geral da turma ficou em 7,24, um conceito bom.

Conclui-se que os resultados foram satisfatórios, entendemos o projeto descrito no artigo nos motiva a continuar e que ensinar lógica e programação no ensino médio é possível, o curso pode ajudar o aluno ao cursar o ensino superior, pois a maioria dos curso possuem a disciplina de programação, motivando o aluno da escola pública concluir o ensino médio e cursar o ensino superior, além de colaborar no processo de ensino e aprendizagem de futuros docentes de licenciatura em computação.

Como trabalho futuro, pretende-se aumentar a carga horária do curso para aprofundar os algoritmos, aplicar em uma linguagem de programação e disponibilizar todo o material em forma de apostila na plataforma do moodle para os alunos consultarem.

\section{Agradecimento}

O presente trabalho foi realizado com apoio do Programa Institucional de Bolsa de Iniciação à Docência - PIBID, da CAPES - Coordenação de Aperfeiçoamento de Pessoal de Nível Superior - Brasil. 


\section{Referências}

Brasil (2012). Ministério da Educação. Diretrizes Curriculares Nacionais para os cursos de graduação em Computação. Disponível em http://portal.mec.gov.br/index.php?option=com_content $\&$ view=article\&id=12991. Acessado em 31/07/2013.

Forbellone, A. L. V. e Eberspacher ,H. F. (2005). Lógica de Programação. São Paulo: Pearson Prentice Hall.

Garcia, R. E.; Correia, R. C. M.; Shimabukuro, M. H. (2008). Ensino de Lógica de Programação e Estruturas de Dados para Alunos do Ensino Médio, In: Anais do XXVIII Congresso da SBC, WEI-XVI Workshop sobre Educação em Computação. Belém, Brasil.

Leal, W. S. Lozano A.R.G. (2009). A Viabilidade do Ensino de Algoritmos no Ensino Médio. In; IX Congresso Nacional de Educação- III Encontro de Psicopedagogia. PUCPR, Brasil.

Marques, D. L.; Costa, L. F. S. C.; Silva, M. A. A. ; Rebouças, A. D. D. S. (2011). Atraindo Alunos do Ensino Médio para a Computação: Uma Experiência Prática de Introdução a Programação utilizando Jogos e Python. In Anais do Simpósio Brasileiro de Informática na Educação - XVII WIE. Aracajú, Brasil.

Moraes, M. C. (1997). O paradigma educacional emergente. São Paulo: Papirus.

Nunes, D. J. (2004). Projetos de Planos Pedagógicos Orientados a Problemas. Sociedade Brasileira de Computação.

Pereira Júnior, J.; Rapkiewicz, C.E.; Delgado, C.; Xexeo, J.A.M. (2005) "Ensino de Algoritmos e Programação: Uma Experiência no Nível Médio". In Anais do XXV Congresso da SBC, WEI-XIII Workshop de Educação em Computação. São Leopoldo, Brasil.

Pereira Junior, J. C. R.; Rapkiewicz, C. E. ; Xexeo, J. A. M. ; Delgado, Carla. (2006). AVEP - Um Ambiente de Apoio ao Ensino de Algoritmos e Programação. In Anais do XXVI Congresso da SBC, WEI-XIV Workshop sobre Educação em Computação. Campo Grande, Brasil.

Puga, S., R. G. (2003). Lógica de programação. São Paulo: Prentice Hall.

Scaico, P. D.; Lopes D.; Azevedo, M. A.; Silva, J. C. da; Mendes Neto, S. V. ; Falcão, E. de S. F. (2012). Implementação de um Jogo Sério para o Ensino de Programação para Alunos do Ensino Médio Baseado em m-learning. In Anais do XXXII Congresso da SBC, WEI-XX Workshop sobre Educação em Computação. Curitiba, Brasil. 